\title{
Detection of gastric cancer using transabdominal ultrasonography is associated with tumor diameter and depth of invasion
}

\author{
MINORU TOMIZAWA ${ }^{1}$, FUMINOBU SHINOZAKI ${ }^{2}$, KAZUNORI FUGO $^{3}$, RUMIKO HASEGAWA ${ }^{4}$, \\ YOSHINORI SHIRAI ${ }^{4}$, YASUFUMI MOTOYOSHI ${ }^{5}$, TAKAO SUGIYAMA ${ }^{6}$, \\ SHIGENORI YAMAMOTO ${ }^{7}$, TAKASHI KISHIMOTO ${ }^{3}$ and NAOKI ISHIGE $^{8}$
}

\begin{abstract}
Departments of ${ }^{1}$ Gastroenterology, ${ }^{2}$ Radiology and ${ }^{3}$ Molecular Pathology, National Hospital Organization Shimoshizu Hospital, Yotsukaido, Chiba 284-0003; Departments of ${ }^{4}$ Surgery, ${ }^{5}$ Neurology, ${ }^{6}$ Rheumatology, ${ }^{7}$ Pediatrics and ${ }^{8}$ Neurosurgery, National Hospital Organization Shimoshizu Hospital, Yotsukaido, Chiba 284-0003, Japan
\end{abstract}

Received October 5, 2014; Accepted August 11, 2015

DOI: $10.3892 / \mathrm{etm} .2015 .2718$

\begin{abstract}
Gastric cancer is occasionally diagnosed using transabdominal ultrasonography (US) during screening or investigation of patients with abdominal symptoms. Therefore, the present study analyzed the association of the tumor diameter, pathological T (pT) staging and depth of invasion with the detection of gastric cancer using US. Patient records were analyzed retrospectively and 13 patients were enrolled, who underwent US screening prior to endoscopic mucosal resection, endoscopic submucosal dissection or surgery. In total, 5 patients were diagnosed with gastric cancer using US (positive detection group), while US was unable to detect the gastric cancer in 8 patients (negative detection group). The tumor diameter and depth of invasion were determined by pathologists. One-way analysis of variance or the $\chi^{2}$ test was performed. Wall thickness in gastric cancer cases ranged between 7 and $20 \mathrm{~mm}$ (mean, $12.2 \pm 5.9 \mathrm{~mm}$ ), as measured using abdominal US. The hemoglobin level was significantly lower in the positive detection patients compared with the negative detection patients $(\mathrm{P}=0.0455)$. In addition, the diameters of the gastric wall in the negative and positive detection patients were $24.5 \pm 16.4$ and $54.4 \pm 26.2 \mathrm{~mm}$, respectively $(\mathrm{P}=0.0266)$. These results indicate that gastric cancer in the positive detection patients were at a more advanced-stage compared with that in the negative detection patients. Furthermore, gastric cancer with a stage over $\mathrm{pT} 2$ was diagnosed using abdominal US $(\mathrm{P}=0.0242)$, whereas stage pTla gastric cancer was not detected by abdominal US. Gastric tumors invading deeper than the submucosa were diagnosed using US ( $\mathrm{P}=0.0242)$. However, the gastric cancer cases limited to the mucosa
\end{abstract}

Correspondence to: Dr Minoru Tomizawa, Department of Gastroenterology, National Hospital Organization Shimoshizu Hospital, 934-5 Shikawatashi, Yotsukaido, Chiba 284-0003, Japan E-mail: nihminor-cib@umin.ac.jp

Key words: gastric cancer, transabdominal ultrasonography, $\mathrm{T}$ staging, tumor diameter, depth of invasion remained undetected. In conclusion, the detection of gastric cancer correlated well with the tumor diameter, pT staging and depth of invasion.

\section{Introduction}

Gastric cancer is common condition world wide, although with an incidence rate lower than those of lung, breast and colorectal cancer (1). Symptoms of gastric cancer include anemia, weigh loss, appetite loss, easy fatigability and non-specific symptoms such as abdominal pain (2). Treatment options for gastric cancer include endoscopic treatment, surgery, chemotherapy and radiation $(1,3,4)$. Key types of endoscopic treatment include endoscopic mucosal resection (EMR) and endoscopic submucosal dissection (ESD) $(5,6)$. Despite improvements in treatment efficacy, prognoses for gastric cancer remain poor (7). A potential reason for this may be that patients are diagnosed on the basis of advanced symptoms of late stage gastric cancer, which limits their treatment options. Therefore, effective screening is essential for the improvement of outcome of patients with early stage gastric cancer that exhibits relatively few symptoms (8). Currently, radiographic and endoscopic screening methods are in use (9).

Endoscopy is the gold standard of diagnosis of gastric cancer (10). However, endoscopy is not always performed for screening in countries with a relatively low number of the patients, and endoscopic resources may be limited (8). Furthermore, endoscopy is not always performed for patients with abdominal symptoms, as these patients are often subjected to transabdominal ultrasonography (US). US is useful for the diagnosis of diseases in solid organs, including the liver, biliary system and pancreas (11). US may be performed for patients with abdominal pain and diagnose diseases of alimentary tracts (12). US often reveals gastrointestinal diseases presenting to the hospital with an acute abdomen $(13,14)$. In addition, gastrointestinal cancer is occasionally detected using US (15). Gastric cancer may be incidentally diagnosed in patients with nonspecific symptoms that undergo US screening (16).

In the present study, we retrospectively analyzed the records of patients that were diagnosed with gastric cancer, and their specimens were available due to surgery or endoscopical treatment. A variety of factors were investigated that 
Table I. Patient characteristics.

\begin{tabular}{|c|c|c|c|c|}
\hline Characteristics & Normal range & Negative detection $^{\mathrm{a}}$ & Positive detection $^{\mathrm{a}}$ & P-value \\
\hline Patients (n) & - & 8 & 5 & - \\
\hline Gender (male:female) & - & $6: 2$ & $2: 3$ & - \\
\hline Mean age (years) & - & $72.8 \pm 5.3$ & $65.8 \pm 11.6$ & 0.1654 \\
\hline Age range (years) & - & $67-81$ & $47-76$ & - \\
\hline $\mathrm{WBC}(\operatorname{per} \mu \mathrm{l})$ & $3500-8500$ & $7,366 \pm 2647$ & $7380 \pm 2464$ & 0.9904 \\
\hline CRP (mg/dl) & $<0.3$ & $1.08 \pm 1.70$ & $2.18 \pm 2.75$ & 0.3053 \\
\hline $\mathrm{Hb}(\mathrm{g} / \mathrm{dl})$ & $13.5-17.0$ & $13.8 \pm 2.5$ & $10.9 \pm 3.6$ & 0.0455 \\
\hline T-Bil (mg/dl) & $0.30-1.20$ & $0.73 \pm 0.52$ & $0.60 \pm 0.32$ & 0.5360 \\
\hline ALP (IU/1) & $115-359$ & $242 \pm 75$ & $246 \pm 64$ & 0.9072 \\
\hline AST (IU/l) & $13-33$ & $23.3 \pm 8.3$ & $25.9 \pm 15.6$ & 0.6271 \\
\hline ALT (IU/l) & $8-42$ & $20.8 \pm 12.2$ & $22.2 \pm 19.8$ & 0.8447 \\
\hline g-GTP (IU/l) & $10-47$ & $36.8 \pm 22.0$ & $59.7 \pm 63.1$ & 0.2608 \\
\hline CEA (ng/ml) & $<5.0$ & $148 \pm 435$ & $180 \pm 437$ & 0.8824 \\
\hline CA19-9 (U/ml) & $<37$ & $16.6 \pm 15.1$ & $1541 \pm 4266$ & 0.2985 \\
\hline Wall thickness, mean (mm) & - & $3.7 \pm 1.0$ & $12.2 \pm 5.9$ & 0.0008 \\
\hline Wall thickness, range (mm) & - & $2-5$ & $7-20$ & - \\
\hline
\end{tabular}

${ }^{a}$ Detection of gastric cancer using abdominal US. The gastric wall thickness in gastric cancer cases was measured using abdominal US. Data are expressed as the mean \pm standard deviation or a range. One-way analysis of variance was performed. US, ultrasonography. WBC, white blood cell; CRP, C-reactive protein; Hb, hemoglobin; T-Bil, total bilirubin; ALP, alkaline phosphatase; ALT, alanine aminotransferase; AST, aspartate aminotransferase; g-GTP, $\gamma$-glutamyl transpeptidase; CEA, carcinoembryonic antigen; CA19-9, carbohydrate antigen 19-9.

were associated with the detection of gastric cancer using US, including the limitations in using US to diagnose gastric cancer.

\section{Materials and methods}

Patients. The records of patients admitted to the National Hospital Organization Shimoshizu Hospital (Yotsukaido, Japan) between November 2011 and July 2014 were retrospectively analyzed. Patients included in this study had undergone surgery, EMR or ESD subsequent to the diagnosis of gastric cancer on the basis of biopsy specimens, and were subjected to US prior to endoscopy, in order to diagnose the patient. A total of 13 patients met the inclusion criteria and were enrolled into this study, including 8 male (mean age \pm standard deviation, $69.3 \pm 3.8$ years) and 5 female patients $(71.4 \pm 13.9$ years). Patients were divided into the following two groups: Negative detection group, consisting of patients in which gastric cancer was not detected using US; and positive detection group, consisting of patients in which gastric cancer was detected using US.

This study was subjected to review by the Ethical Committee of the National Hospital Organization Shimoshizu Hospital, and was not considered as a clinical trial, since it was performed as a part of routine clinical practice. The present study was retrospective and patient anonymity was preserved, thus informed consent was not required.

Transabdominal US. US was performed using the SSA-700A ultrasound system (Toshiba Medical Systems Corporation, Ohtawara, Japan) with a $3.75-\mathrm{MHz}$ curved-array probe
(PVT-375BT) or an 8.0-MHz linear-array probe (PLT-805AT) in the US unit. US was performed by board-certified fellows of the Japan Society of Ultrasonics in Medicine (Tokyo, Japan) (http://www.jsum.or.jp/jsum-e/index.html). Gastric cancer was diagnosed upon detection of irregular wall thickness as compared with the surrounding lesions, or when loss of stratification was observed (15).

Pathological analysis. The tumor diameter and depth of invasion were determined by the pathologists using specimens. Specimens were obtained through surgery, EMR or ESD, which were performed in our hospital. Pathological T (pT) staging of the specimens obtained via surgery, EMR or ESD, was performed by the pathologists, based on the classification described by the American Joint Committee on Cancer (7th edition) (17), as follows: pT1a, lamina propria or muscularis mucosae; pT1b, submucosa; pT2, muscularis propria; pT3, subserosal connective tissue without invasion of visceral peritoneum or adjacent structures; and pT4, seroa (visceral peritoneum) or adjacent structures. The staging was decided on consensus between two pathologists.

Statistical analysis. JMP software, version 10.0.2 (SAS Institute, Cary, NC, USA) was used for statistical analysis. One-way analysis of variance was applied to variables of patient characteristics and tumor diameter between the negative and positive detection groups. The $\chi^{2}$ test was used to determine the association of depth of invasion and $\mathrm{T}$ staging between the negative and positive detection groups. A P-value of $<0.05$ was considered to indicate a statistically significant difference. 
Table II. Correlation of gastric cancer detection using ultrasonography with depth of invasion or pathological T staging.

\begin{tabular}{lccccr}
\hline & \multicolumn{2}{c}{$\mathrm{pT}$ staging $(\mathrm{P}=0.0242)$} & & \multicolumn{2}{c}{ Invasion depth $(\mathrm{P}=0.0242)$} \\
\cline { 2 - 3 } Group & $>\mathrm{pT} 2$ & $\mathrm{pT1a}$ & $>\mathrm{SM}$ & $\mathrm{M}$ & Total \\
\hline Positive detection $^{\mathrm{a}}$ & 5 & 0 & 5 & 0 & 5 \\
Negative detection $^{\mathrm{a}}$ & 3 & 5 & 3 & 5 & 8 \\
Total & 8 & 5 & 8 & 5 & 13 \\
\hline
\end{tabular}

${ }^{a}$ Detection of gastric cancer using abdominal US. The pathological T staging was determined following the classification of the American Joint Committee on Cancer (7th edition). $>$ SM, deeper than the submucosa; $M$, mucosa; $>$ pT2, above stage pT2. P=0.0242 ( $\chi^{2}$ test).
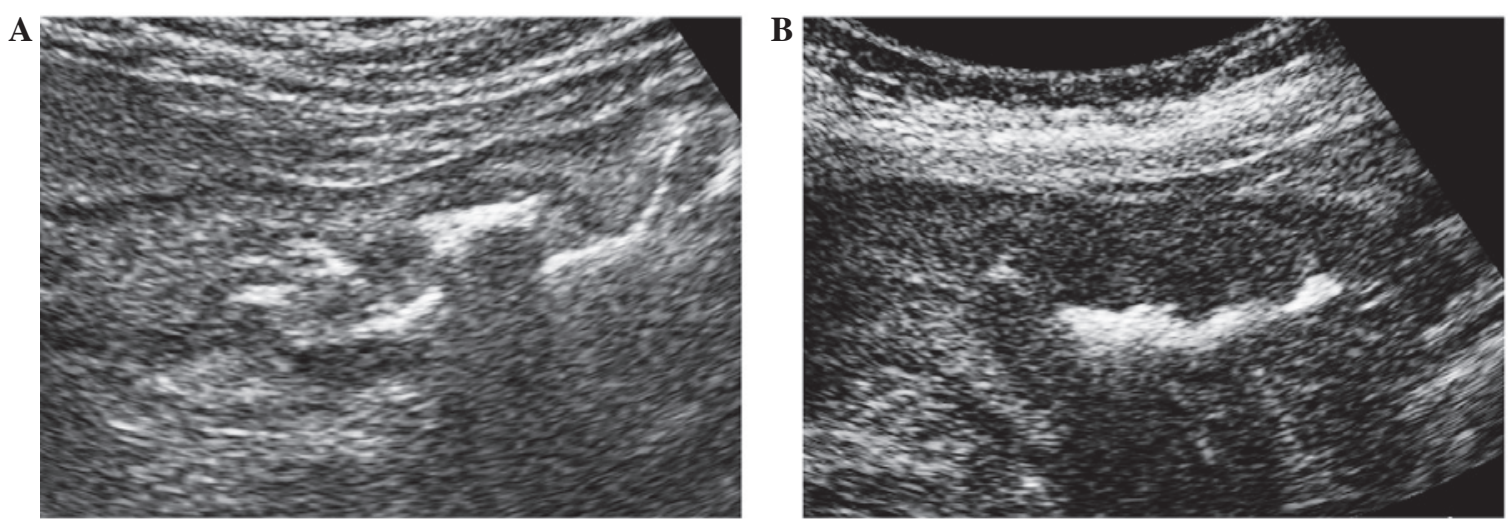

Figure 1. Ultrasonography findings in representative gastric cancer cases. (A) A 63-year-old male was subjected to ultrasonography for screening. A thickened gastric wall with depression can be seen. (B) A 47-year-old female visited our hospital with weight loss and a thickened gastric wall.

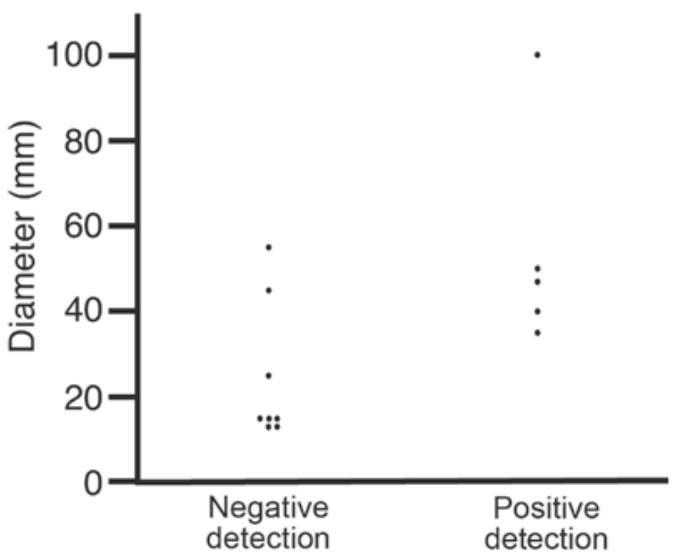

Figure 2. Scatterplot of the diameters of the gastric tumors that were detected (positive detection) or not detected (negative detection) using abdominal ultrasonography, which were $54.4 \pm 26.2$ and $24.5 \pm 16.4 \mathrm{~mm}$, respectively $(\mathrm{P}=0.0266$; one-way analysis of variance).

\section{Results}

US findings. On US images, gastric cancer tumors were detected as thickening of the gastric wall (Fig. 1A and B) (8). Gastric wall thickening may be observed as a symptom of gastric ulcer (18); however, irregularity of the edge of the thickened wall is a hallmark of gastric cancer (8). All of the present patients with gastric wall thickening were diagnosed with gastric cancer using upper gastrointestinal endoscopy. In certain patients, depression of the center of the gastric wall thickening was clearly demonstrated (Fig. 1B). A total of 5 patients were diagnosed with gastric cancer using US, whereas US did not detect evidence of cancer in 8 others.

Patient characteristics. Patient characteristics are presented in Table I. The hemoglobin level was significantly lower in the positive detection patients compared with that in the negative detection patients $(\mathrm{P}=0.0455)$. This was probably due to tumor bleeding (19). No statistically significant differences in the other parameters were detected between the two groups. Gastric wall thickness was $3.7+1.0 \mathrm{~mm}$ in negative detection and $12.2 \pm 5.9 \mathrm{~mm}$ in positive detection $(\mathrm{P}<0.01)$. Larsen et al reported that gastric wall thickness in normal healthy subjects is $3.27 \pm 0.42 \mathrm{~mm}(20)$. It was clear that the gastric wall was thicker in the positive detection patients compared with the normal subjects.

Tumor diameter. The tumor diameters were analyzed in the specimens obtained via surgery, EMR or ESD (Fig. 2). The diameters of the negative and positive detection patients were $24.5 \pm 16.4$ and $54.4 \pm 26.2 \mathrm{~mm}$, respectively $(\mathrm{P}=0.0266)$. No gastric cancer tumors $<30 \mathrm{~mm}$ were detected, indicating that US detected gastric cancer tumors $>30 \mathrm{~mm}$.

Correlation of gastric cancer detection with $p T$ staging and depth of invasion. The effect of pT staging and depth of invasion on the detection of gastric cancer using US was also analyzed (Table II). Diagnosis was successful using US for gastric cancer tumors above stage pT2 $(\mathrm{P}=0.0242)$. By contrast, 
stage $\mathrm{pT} 1$ gastric cancer tumors remained undetected. Tumors invading deeper than the submucosa were also diagnosed using US $(\mathrm{P}=0.0242)$, whereas cases of gastric cancer limited to the mucosa remained undetected.

\section{Discussion}

Gastric cancer can be detected during US screening (15) and such tumors are diagnosed upon observation of a thickened gastric wall, destruction of the wall structure (loss of stratification) and, occasionally, a hypoechoic mass (16). If patients drink water prior to undergoing a US scan, the gastric wall is visualized as a five-layered structure (21). Loss of stratification indicates destruction of the normal structure of the gastric wall. The presence of gastric cancer should be considered when a wall thickness of $>10 \mathrm{~mm}$ is observed (22). In the present study, wall thickness ranged between 7 and $20 \mathrm{~mm}$ (mean, 12.2 $\pm 5.9 \mathrm{~mm}$ ). Certain patients were diagnosed with gastric cancer when a wall thickness of $<10 \mathrm{~mm}$ was detected, which was due to the presence of irregular-shaped wall thickness or loss of stratification compared with the surrounding tissues.

In the present study, tumor diameters were larger in cases of gastric cancer detected using US compared with cases in which cancer was not detectable using US. In addition, the hemoglobin level was lower in gastric cancer cases detected using US compared with the negative detection patients, possibly due to tumor bleeding (19). These results indicated that gastric cancers that were detected using US were at a more advanced stage compared with those that were not detectable using US. The advancement of gastric cancer is represented with T staging (23), which can be evaluated using transabdominal US with patients drinking water prior to the scan, or using endoscopic US $(24,25)$. In the current study, it was difficult to evaluate pT staging using US as the patients did not consume water prior to screening, and thus pT staging was evaluated subsequent to surgical resection. The results clearly indicated that cases in which gastric cancer was detected using US were at a more advanced stage of the disease compared with those in which gastric cancer was not detectable using US, and no pT1a stage gastric cancer cases were detected using US. In addition, T staging is determined on the basis of the depth of invasion; thus, a pathological analysis of the correlation between the detection of gastric cancer and the depth of invasion was conducted. Gastric cancer that was detected using US invaded deeper than the submucosa. However, none of the gastric cancer cases limited to the mucosa were detectable using US.

In conclusion, the present study demonstrated that the detection of gastric cancer using US correlated with the tumor diameter, pT staging and depth of invasion, and that US was able to detect advanced gastric cancer. In future studies, more patients should be enrolled, and loss of stratification should be investigated with color Doppler imaging and contrast enhancement $(26,27)$.

\section{References}

1. Marrelli D, Polom K, de Manzoni G, Morgagni P, Baiocchi GL and Roviello F: Multimodal treatment of gastric cancer in the west: Where are we going? World J Gastroenterol 21: 7954-7969, 2015.
2. Takahashi T, Saikawa Y and Kitagawa Y: Gastric cancer: Current status of diagnosis and treatment. Cancers (Basel) 5: 48-63, 2013.

3. Yamamoto M, Rashid OM and Wong J: Surgical management of gastric cancer: The East vs. West perspective. J Gastrointest Oncol 6: 79-88, 2015.

4. Papadimitriou K, Antoniou G, Rolfo C, Russo A, Bronte G, Vassiliou V, Papamichael D, Peeters M and Kountourakis P: Adjuvant chemoradiation therapy in gastric cancer: Critically reviewing the past and visualizing the next step forward. Gastroenterol Res Pract 2015: 650846, 2015.

5. Peng LJ, Tian SN, Lu L, Chen H, Ouyang YY and Wu YJ: Outcome of endoscopic submucosal dissection for early gastric cancer of conventional and expanded indications: Systematic review and meta-analysis. J Dig Dis 16: 67-74, 2015.

6. Facciorusso A, Antonino M, Di Maso M and Muscatiello N: Endoscopic submucosal dissection vs endoscopic mucosal resection for early gastric cancer: A meta-analysis. World J Gastrointest Endose 6: 555-563, 2014.

7. Rosa F, Alfieri S, Tortorelli AP, Fiorillo C, Costamagna G and Doglietto GB: Trends in clinical features, postoperative outcomes, and long-term survival for gastric cancer: A Western experience with 1,278 patients over 30 years. World J Surg Oncol 12: 217, 2014.

8. Choi IJ: Endoscopic gastric cancer screening and surveillance in high-risk groups. Clin Endosc 47: 497-503, 2014.

9. Choi KS and Suh M: Screening for gastric cancer: the usefulness of endoscopy. Clin Endosc 47: 490-496, 2014.

10. Moon HS: Improving the endoscopic detection rate in patients with early gastric cancer. Clin Endosc 48: 291-296, 2015.

11. Beggs AD and Thomas PR: Point of use ultrasound by general surgeons: review of the literature and suggestions for future practice. Int J Surg 11: 12-17, 2013

12. Goto R, Arai K, Kitada H, Ogoshi K and Hamashima C: Labor resource use for endoscopic gastric cancer screening in Japanese primary care settings: A work sampling study. PLoS One 9: e88113, 2014.

13. Puylaert JB: Ultrasound of acute GI tract conditions. Eur Radiol 11: 1867-1877, 2001

14. Lameris W, van Randen A, Dijkgraaf MG, Bossuyt PM, Stoker J and Boermeester MA: Optimization of diagnostic imaging use in patients with acute abdominal pain (OPTIMA): Design and rationale. BMC Emerg Med 7: 9, 2007.

15. Tomizawa M, Shinozaki F, Hasegawa R, Fugo K, Shirai Y, Ichiki N, Sugiyama T, Yamamoto S, Sueishi M and Yoshida T: Screening ultrasonography is useful for the diagnosis of gastric and colorectal cancer. Hepatogastroenterology 60: 517-521, 2013.

16. O'Malley ME and Wilson SR: US of gastrointestinal tract abnormalities with CT correlation. Radiographics 23: 59-72, 2003.

17. American Joint Committee on Cancer (AJCC): AJCC Cancer Staging Handbook. 7th edition. Springer-Verlag, New York, USA, 2010.

18. Allen BC, Tirman P, Tobben JP, Evans JA and Leyendecker JR: Gastroduodenal ulcers on CT: Forgotten, but not gone. Abdom Imaging 40: 19-25, 2015.

19. Tomizawa M, Shinozaki F, Hasegawa R, Togawa A, Shirai Y, Ichiki N, Motoyoshi Y, Sugiyama T, Yamamoto S and Sueishi M: Reduced hemoglobin and increased C-reactive protein are associated with upper gastrointestinal bleeding. World J Gastroenterol 20: 1311-1317, 2014.

20. Larsen MC, Yan BM, Morton J and Van Dam J: Determination of the relationship between gastric wall thickness and body mass index with endoscopic ultrasound. Obes Surg 21: 300-304, 2011.

21. Kimmey MB, Martin RW, Haggitt RC, Wang KY, Franklin DW and Silverstein FE: Histologic correlates of gastrointestinal ultrasound images. Gastroenterology 96: 433-441, 1989.

22. Martínez-Ares D, Alonso-Aguirre PA, Souto-Ruzo J, Martín-Granizo-Barrenechea I, Pereira-Bueno S, Cid-Gómez L and Rodríguez-Prada JI: Ultrasonography is an accurate technique for the diagnosis of gastrointestinal tumors in patients without localizing symptoms. Rev Esp Enferm Dig 101: 773-786, 2009.

23. Washington K: 7th edition of the AJCC cancer staging manual: Stomach. Ann Surg Oncol 17: 3077-3079, 2010.

24. Liao SR, Dai Y, Huo L, Yan K, Zhang L, Zhang H, Gao W and Chen MH: Transabdominal ultrasonography in preoperative staging of gastric cancer. World J Gastroenterol 10: 3399-3404, 2004. 
25. Jürgensen C, Brand J, Nothnagel M, Arit A, Neser F, Habeck JO, Schreiber S, Stölzel U, Zeitz M and Hampe J: Prognostic relevance of gastric cancer staging by endoscopic ultrasound. Surg Endosc 27: 1124-1129, 2013.

26. Wei F, Huang P, Li S, Chen J, Zhang Y, Hong Y, Wei S and Cosgrove D: Enhancement patterns of gastric carcinoma on contrast-enhanced ultrasonography: Relationship with clinicopathological features. PLoS One 8: e73050, 2013.
27. Chen CN, Lin JJ, Lee H, Cheng YM, Chang KJ, Hsieh FJ, Lai HS, Chang CC and Lee PH: Association between color doppler vascularity index, angiogenesis-related molecules, and clinical outcomes in gastric cancer. J Surg Oncol 99: 402-408, 2009. 